\title{
Impact of a mutation causing a deficiency of clotting factor on the incidence, productivity and reproduction of cows
}

\author{
Natalia Kovalyuk ${ }^{1}$, Natalia Basova ${ }^{1}$, Mikhail Staroselov ${ }^{1 *}$, Ludmila Yakusheva $^{1}$, Julia \\ Shakhnazarova $^{1}$, and Vitaly Novikov ${ }^{1}$ \\ ${ }^{1}$ Federal State Budgetary Scientific Institution «Krasnodar Scientific Center for Animal Science and \\ Veterinary Medicine», 350004, Krasnodar, 1 line st., 1., Russia
}

\begin{abstract}
As a result of the study, new knowledge was obtained for the first time about the effect of the FXI locus polymorphism on the quality of reproduction in dairy cattle, the degree of influence of the FXI polymorphism on the frequency of development of pathologies of the reproductive organs, their clinical manifestation in individuals - carriers of the anomaly and healthy animals was established. The influence of the FXI locus polymorphism on embryonic and postembryonic mortality, clinical condition and safety of newborn calves in comparison with individuals without a genetic defect was determined.
\end{abstract}

\section{Introduction}

The increase in livestock production directly depends on the stabilization of the cattle population in dairy farms, the technologically sound rearing of replacement young animals and the growth of animal productivity. In the system of these measures, work on the reproduction of the herd is especially important.

To ensure the technological rhythm of herd reproduction, it is necessary to receive 10$11 \%$ of calving every month, to carry out $14-16 \%$ of inseminations at $55-60 \%$ fertility and $8-9 \%$ conception of pregnancy from the livestock at the beginning of the year. For such a rhythm of reproduction, not only complete feeding and proper maintenance of cows are required, but also the use of a clear scientifically grounded system of control and regulation of reproductive function [1]. Every year, agricultural enterprises reject 20-25\% of highly productive cows due to obstetric and gynecological diseases. Among them are animals that are highly valuable in breeding terms. Therefore, there is an urgent need for constant monitoring of the state of reproductive function in cows and heifers in order to obtain optimal offspring and maximize their milk productivity $[2-5,16]$.

Until recently, a decrease in the reproductive capacity of cows was associated mainly with postpartum problems of a clinical nature, as well as with the development of metabolic stress due to lactation. In the light of recent scientific evidence, the deterioration of reproductive qualities is increasingly associated with an increase in the genetic burden in the cattle population.

\footnotetext{
*Correcting author: va.hills.staroselov@gmail.com
} 
The accumulation of various kinds of mutations is associated with the intensive use in artificial insemination of bulls - hidden carriers and the possible association of mutant genes with indicators of milk productivity. Artificial insemination leads to the fact that a bull carrying a mutation in a latent state can transmit it to thousands or even tens of thousands of daughters and sons.

Factor XI deficiency (FXID) in bovine blood clotting is an autosomal recessive inherited genetic defect. Cows that are heterozygous carriers of this defect are susceptible to pneumonia, mastitis and endometritis. In 2004, it was found that FXID is a consequence of the insertion of a nucleotide sequence of 76 pairs (AT(A)28TAAAG(A)26GGAAATAATAATTCA) bases in exon 12 of the FXI gene, which leads to the formation of a STOP codon (TAA) and disrupts the normal functioning of the gene [6].

In various countries, active testing of livestock subpopulations has been carried out in order to eliminate this genetic anomaly $[7,8,9]$. The frequency of occurrence of carriers was at the level of $0.85-2.33 \%$. Screening studies of 420 heads, carried out in 2012, showed that carriers of mutant alleles in the FXI gene are not found in populations of Holstein and Black-and-White cattle in Russia [10, 13-15]; studies carried out later [11] showed a low frequency of the mutant allele $(0.007)$ in the group of sires $(n=70)$ in the Republic of Tatarstan. In this regard, interest in this anomaly in Russia and the world was practically lost. However, we found that bulls - producers - carriers of mutations in the FXI gene are rare, but they are found, and in those farms where they were used on a large scale, the frequency of occurrence of heterozygous carriers is very significant [12].

\section{Materials and methods}

The research work was carried out on the basis of the department of therapy and obstetrics of the laboratory of biotechnology of the Federal State Budgetary Scientific Institution "Krasnodar Scientific Center for Animal Science and Veterinary Medicine" and the economy of the Krasnodar Region, which has problems with reproduction.

Genetic studies were carried out on 100 Holstein cows, daughters of the bull Athlet 307 (JSC Krasnodarskoye for artificial insemination) - a carrier of a lethal mutation in the FXI gene, laboratory and clinical studies - on 90 cows.

Reagent kits were used to isolate DNA from samples Diatom ${ }^{\mathrm{TM}}$ DNA Prep 100 (LLC "Laboratory Isogen", Moscow). For amplification, primers FXID 1 and FXID 2 [11] were used with the following sequence: FXID 1: 5'CCCACTGGCTAGGAATCGTT3'; FXID 2:5'CAAGGCAATGTCATATCCAC3'. When screening the region of interest in exon 12 of the FXI gene, various amplification conditions were used to select the optimal reaction conditions. The best result in terms of the yield of a specific product was obtained by a polymerase chain reaction with the following amplification conditions: $94^{\circ} \mathrm{C}-4 \mathrm{~min}$.; $\left(94^{\circ} \mathrm{C}-5 \mathrm{~s} ., 65^{\circ} \mathrm{C}-5 \mathrm{~s} ., 72^{\circ} \mathrm{C}-5 \mathrm{~s}\right.$. $)-30$ cycles; $72^{\circ} \mathrm{C}-5 \mathrm{~min}$.

The aim of the research is to assess the effect of the FXI locus polymorphism on the incidence of pathologies of the reproductive organs of Holstein cattle.

To achieve the goal, the following tasks have been identified for study:

- identify among cows - daughters of the bull Athlete 307 carriers of a lethal mutation in the gene FXI;

- to study in a comparative aspect the productivity and reproduction rates of cows carriers of a lethal mutation in the FXI gene and not having genetic abnormalities in this gene. 


\section{Results}

To control the progress of the reaction and assess the quality and concentration of PCR products, electrophoresis in $2 \%$ agarose gel was performed. The carriers of the mutant allele, in addition to a fragment of 244 base pairs in length, showed the presence of a specific fragment with a length of $320 \mathrm{bp}$. (lanes $2,3,5,6,7,8$ ).

The screening results are presented on an electrophoretogram (Fig. 1).

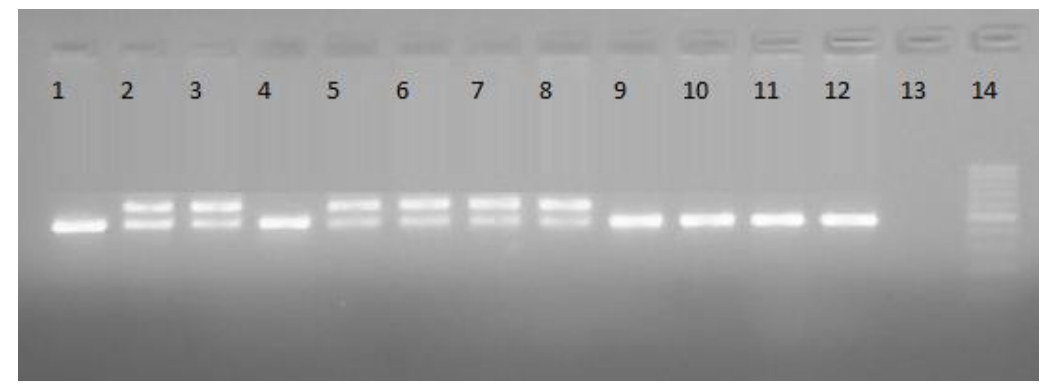

Fig. 1. Electropherogram of gene amplification products FXI. Heterozygous carriers of the FXI gene mutation in lanes: $2,3,5,6,7,8$. Healthy animals on the tracks: 1,4,9-12. Molecular weight marker: lane 14.

As a result of genotyping at the FXI locus, it was found that the frequency of occurrence of heterozygous carriers of the anomaly was 0.47 ; the frequency of occurrence of the mutant allele is 0.24 .

Cows carrying a mutation in the FXI gene, at birth, had a body weight $3.5 \%$ lower than heifers without the mutation; the tendency for a decrease in body weight gain in carriers of the genetic abnormality persisted up to 12 months of age. The age of the first insemination and the first calving in the heifers of the experimental group was 2.3 months higher than in the control, the body weight at the age of 1 insemination was $2.2 \%$ lower (Table 1 ).

Table 1. Effect of FXI locus polymorphism in heifers on body weight, age 1 of insemination and calving. ( $M \pm n, p=45)$.

\begin{tabular}{|c|c|c|c|}
\hline № & Indicators & Control group & $\begin{array}{c}\text { Experienced group } \\
\text { (carriers) }\end{array}$ \\
\hline 1 & Live weight at birth, $\mathrm{kg}$ & $28,7 \pm 0,47$ & $27,7 \pm 0,37$ \\
\hline 2 & Live weight at 6 months of age, $\mathrm{kg}$ & $199,0 \pm 2,33$ & $198,3 \pm 10,65$ \\
\hline 3 & Live weight at 12 months of age, $\mathrm{kg}$ & $306,6 \pm 8,3$ & $303,0 \pm 5,17$ \\
\hline 4 & Age of first insemination, months & $16,0 \pm 0,86$ & $18,3 \pm 2,27$ \\
\hline 5 & Live weight at the first insemination, $\mathrm{kg}$ & $392,0 \pm 8,0$ & $386,5 \pm 3,5$ \\
\hline 6 & Age of 1 calving, months & $24,9 \pm 0,69$ & $27,2 \pm 2,28$ \\
\hline
\end{tabular}

As can be seen from the data shown in Table 1, on average, the heifers in the experimental group had a lower body weight at birth, weight gain up to 12 months of age than in control animals, and the age of first insemination and calving was higher.

When assessing milk productivity for 100 days for 1 and 2 lactations, it was found that for the first lactation in 100 days it was lower by $15 \%$, for the second lactation - by $12.2 \%$ (Fig. 2). 


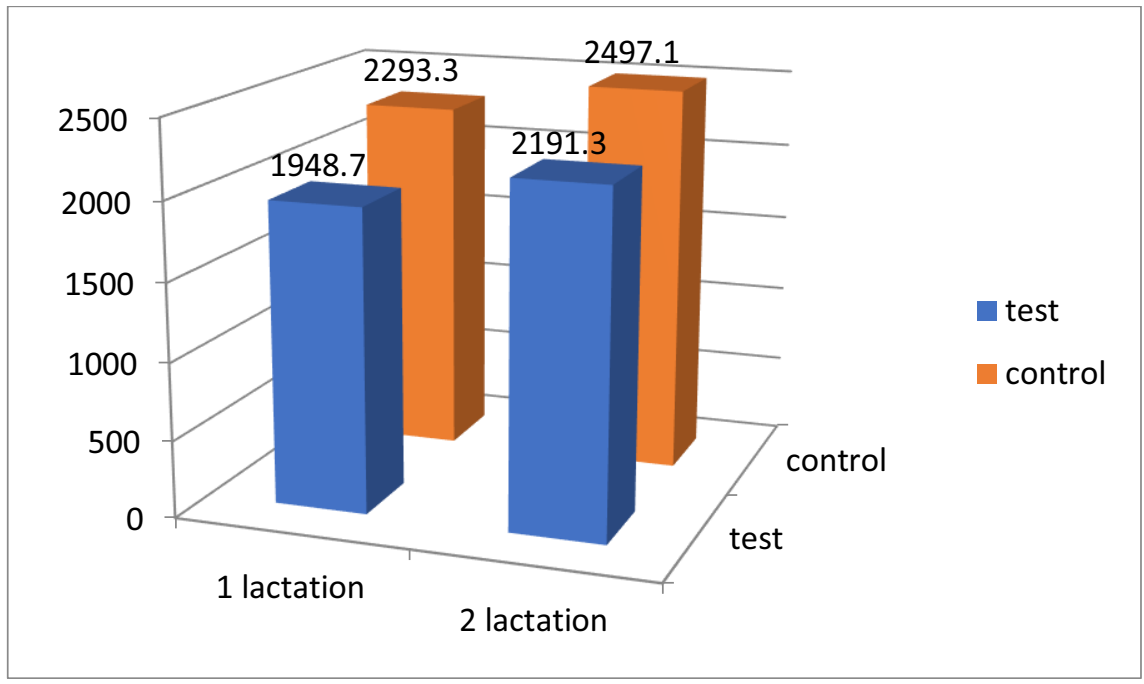

Fig. 2. Influence of polymorphism of loci associated with reproductive qualities on milk production of cows.

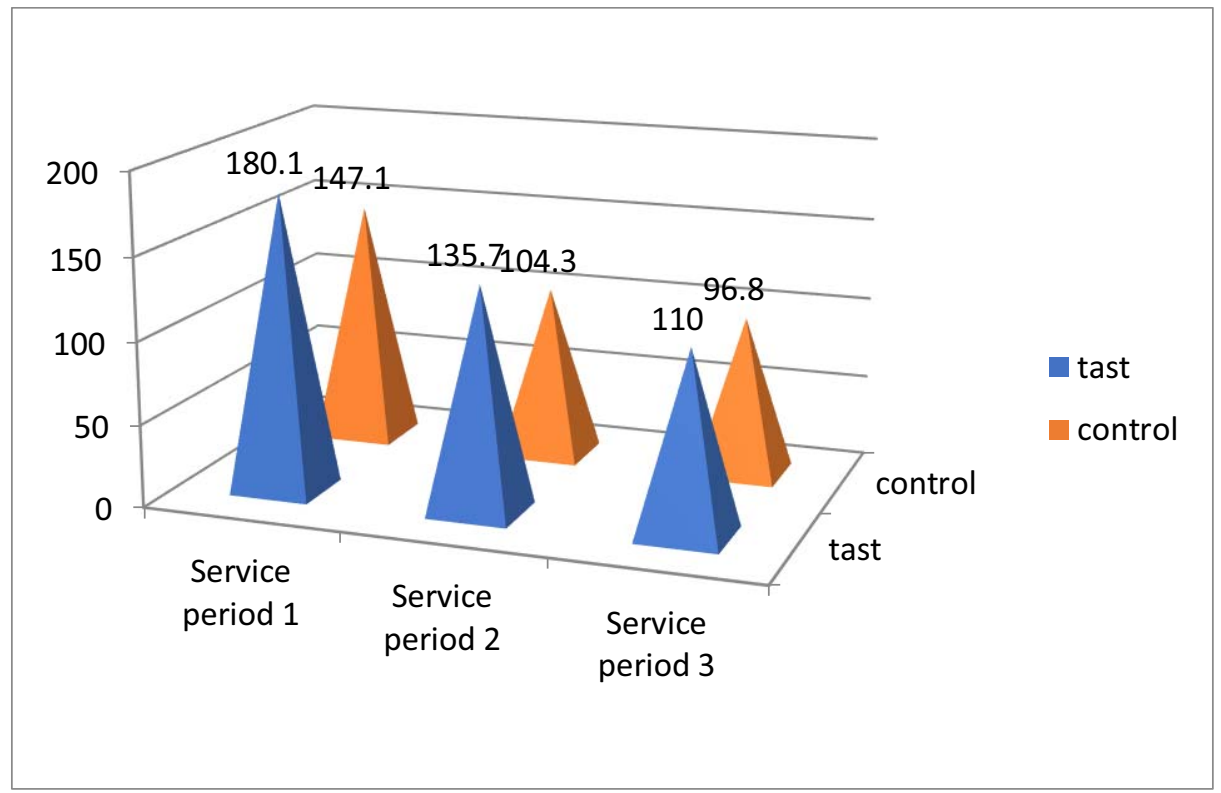

Fig. 3. Influence of polymorphism of loci associated with reproductive qualities on the service period of cows.

Service period 1, 2 and 3 insemination in cows of the experimental group was longer than in control animals, respectively, by $22.4 \%, 29 \%$ and $13.6 \%$ or $33,31.4$ and 13.2 days (Fig. 3).

After analyzing the frequency of the development of pathological processes of the reproductive organs in carriers of loci associated with reproductive qualities, it was found that the number of stillborn calves and aborted fetuses in cows of the experimental group was 2 times higher than in the control, both in the first and second calving, embryonic mortality - by $35 \%$ : in cows of the experimental group - 17 or $37.8 \%$, in the control group 6 heads or $13.3 \%$. Pathologies of childbirth and diseases of reproductive organs after 
calving were noted in 30 cows in the experimental group (66.7\%) and in 13 cows in the control group $-28.9 \%$, which is 2.3 times lower than the control indicator. For one fruitful insemination of cows in the experimental group, an average of 6.8 sperm doses were spent, control -5.2 sperm doses, or $30.8 \%$ less. The retention of the placenta was recorded in 6 cows from the group or $12 \%$; in the cows of the control group, the retention of the placenta was not recorded.

Acute endometritis in cows of the experimental group was recorded after calving in 14 heads of $31.1 \%$ of cases, in control animals - 9 heads or $20 \%$. Abortions and frequent binges were recorded in 4 cows of the experimental group - $8.9 \%$ and in 2 - control $-4.45 \%$ (Fig. 4).

The results of retrospective serological studies of cows taken into the experiment after double immunization with the inactivated vaccine "Kombovac- $\mathrm{R}$ " indicate the presence of active specific antibodies to the IRT causative agent in animals of the experimental group, where the titers of specific antibodies to this antigen were within 1: $134 \pm 100$, and ranged from 1: 8 to 1: 4096. Titers of specific post-vaccination antibodies after immunization of cows with an inactivated vaccine above a value of 1: 512 indicate the development of active immunity as a result of contact of the animal with the pathogen and / or its IRT disease. In the control group, these indicators were 1: $116.4 \pm 60$, respectively, and did not exceed 1: 512.

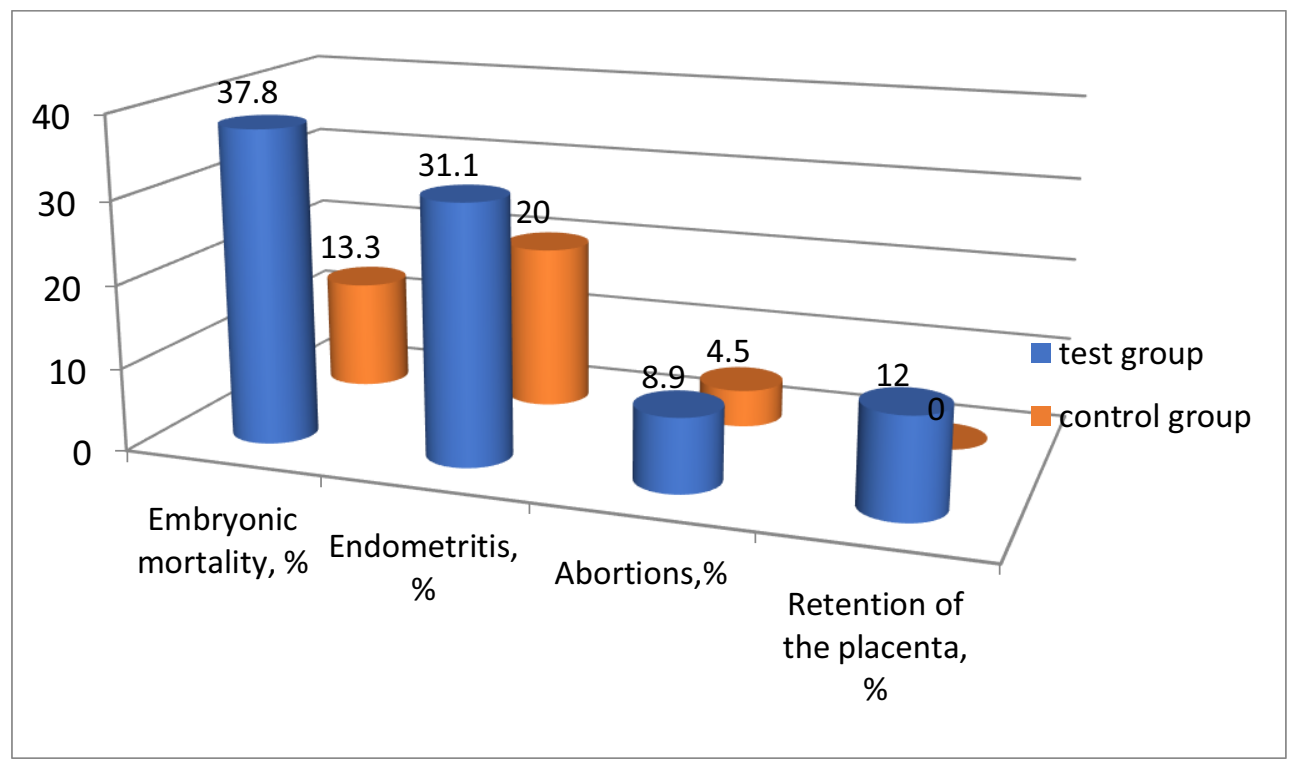

Fig. 4. Influence of polymorphism of loci associated with reproductive qualities on the reproduction rates of cows.

The influence of polymorphism of loci associated with the reproductive qualities of cattle on the clinical state and safety of newborn calves in comparison with offspring obtained from individuals without genetic defects was manifested in a decrease in body weight: the average live weight of calves obtained from cows - carriers of the mutation at birth was $5.6 \%$ lower than in the control group, the incidence of gastrointestinal diseases with diarrheal syndrome in newborn calves is higher by $12.5 \%$, respiratory diseases - by $10.1 \%$. Mortality of calves obtained from cows of the experimental group was $8 \%$ higher. Thus, the presence of polymorphism of loci associated with reproductive qualities negatively affects not only the organism of its carrier, but also the health of the offspring obtained from it. 


\section{Discussion}

As a result of genotyping for the FXI locus, the frequency of occurrence of heterozygous carriers of the anomaly in the daughters of the bull Athlet 307 was established - 47\%.

Carriage of a mutation in the FXI gene negatively affects the body weight of heifers at birth, weight gain, age 1 insemination.

Milk productivity in carriers of the genetic abnormality is lower than that of intact analogs by $15 \%$ lower, by the first and by $12.2 \%$ - by the second lactation.

The incidence of diseases of the reproductive organs after calving in carriers of the genetic anomaly was $37.8 \%$ higher.

\section{Conclusions}

Carriage of a mutation in the FXI gene negatively affects the productivity and reproductive functions of cows. When forming herds of highly productive dairy cattle, one should not use breeding bulls - Carriers of the mutation in the FXI gene, since they transmit a genetic defect to $47 \%$ of daughters, which reduces the productive and reproductive performance of the herd.

\section{References}

1. V.V. Lyashenko, N.A. Balakirev, Yu.A. Yuldashbayev, et al., Bulletin of the National Academy of Sciences of the Republic of Kazakhstan, 1 (383), 72-79 (2020)

2. A. Andriichuk, I. Tkachova, H. Tkachenko, Journal of Equine Veterinary Science, 36, 32-43 (2016)

3. M.A. Crowe, E.J. Willams, J. Anim. Sci., 90, 1722-1727 (2012), DOI: 10.2527/jas.2011-4674)

4. O.K. Gogaev, V.R. Kairov, A.R. Demurova, T. Kadieva, Journal of Dairy \& Veterinary Sciences, 10(4), 1-3 (2019)

5. S. Duga, O. Salomon, Seminars in Thrombosis and Hemostasis, 39(6), 621-631 (2013)

6. K. Avanus, Journal of the Faculty of Veterinary Medicine Istanbul University, 42(2), 190-193 (2016), DOI: 10.16988/iuvfd.2016.53309

7. M.S. Azad, I.D. Gupta, A. Verma, V. Bohra, S.R. Kumar, Current Trends in Biotechnology and Pharmacy, 5(1), 1060-1063 (2011)

8. S.C.A. Bagheri, M. Chamani, M. Aminafshar, A.A. Sadeghi, and H. R. Seyedabadi, Glob. Vet. 8(6), 598-600 (2012)

9. N.A. Zinovieva, E.A. Gladyr, O.V. Kostjunina, et al., Achievements of Science and Technology of the Agro-Industrial Complex, 11, 37-40 (2012)

10. A. Das, F. Panitz, V.R. Gregersen, et al., BMC Genomics, 16(1), 1043 (2015)

11. S. Colakoglu, T. Bayhan, B. Tavil, et al., Blood Transfusion, 16(1), 105-113 (2018)

12. F. Fazio, C. Saoca, G. Piccione, et al., Journal of Equine Veterinary Science, 47, 20-24 (2016)

13. D.M. Muratbayev, O.N. Akhmetzhanov, A.S. Ygieva, Advances in Animal and Veterinary Sciences, 6(10), 436-442 (2018)

14. I.Yu. Dolmatova, T.A. Sedykh, F.R. Valitov, et al., Veterinary World, 13(10), 2046$2052(2020)$ 
15. N.Yu. Basova, M.A. Staroselov, A.K. Shatum, et al., Veterinary of Kuban, 1, 3-5 (2021), DOI:10.33861/2071-8020-2021-1-3-5 